\title{
Quiz: Carotid artery ultrasound
}

A 60-year-old female outpatient with complaints of episodes of tachycardia was referred to the ultrasound department by her cardiologist. She was sent for carotid artery ultrasound as a significant carotid plaque was noted during a previous thyroid ultrasound (carotid artery bifurcation screening must be performed as part of thyroid ultrasound at our clinic).
It was started as a routine carotid artery ultrasound examination. However, possible surgical correction was considered in this case due to findings. In order to present this case to a vascular surgeon correctly, we have to use the multiparametric approach. Some of the images are demonstrated below (Fig. 1-4).

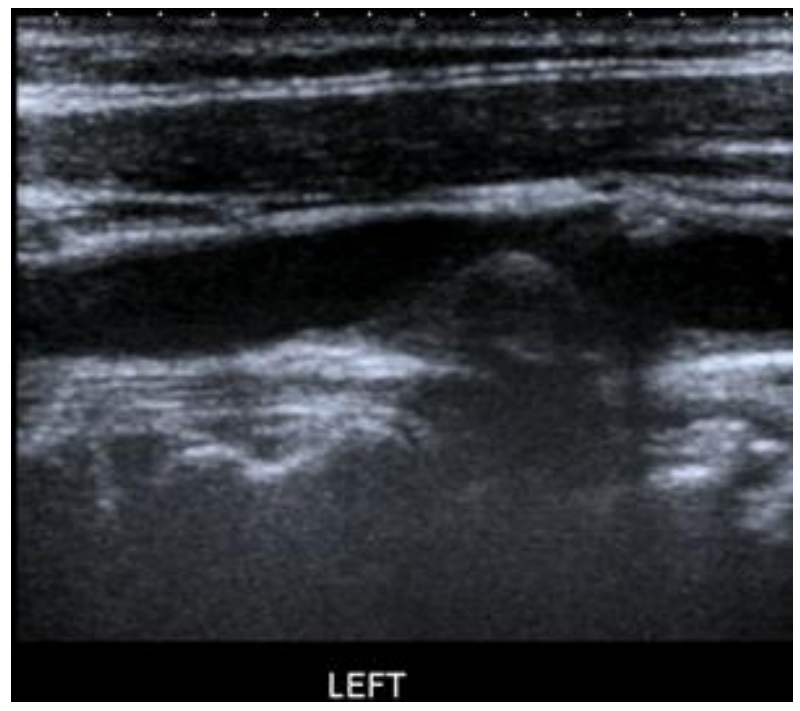

Figure 1. Proximal segment of the left Internal carotid artery (left ICA)

Address for Correspondence: Ihor Hayda, Danylo Halytsky Lviv National Medical University, Lviv, Ukraine, Email:

ihayda@gmail.com

Received: 16.04.2020 Revised: 13.05.2020 Accepted: 14.05 .2020

Copyright $@ 2020$ Heart, Vessels and Transplantation

doi: 10.24969/hvt.2020.195 


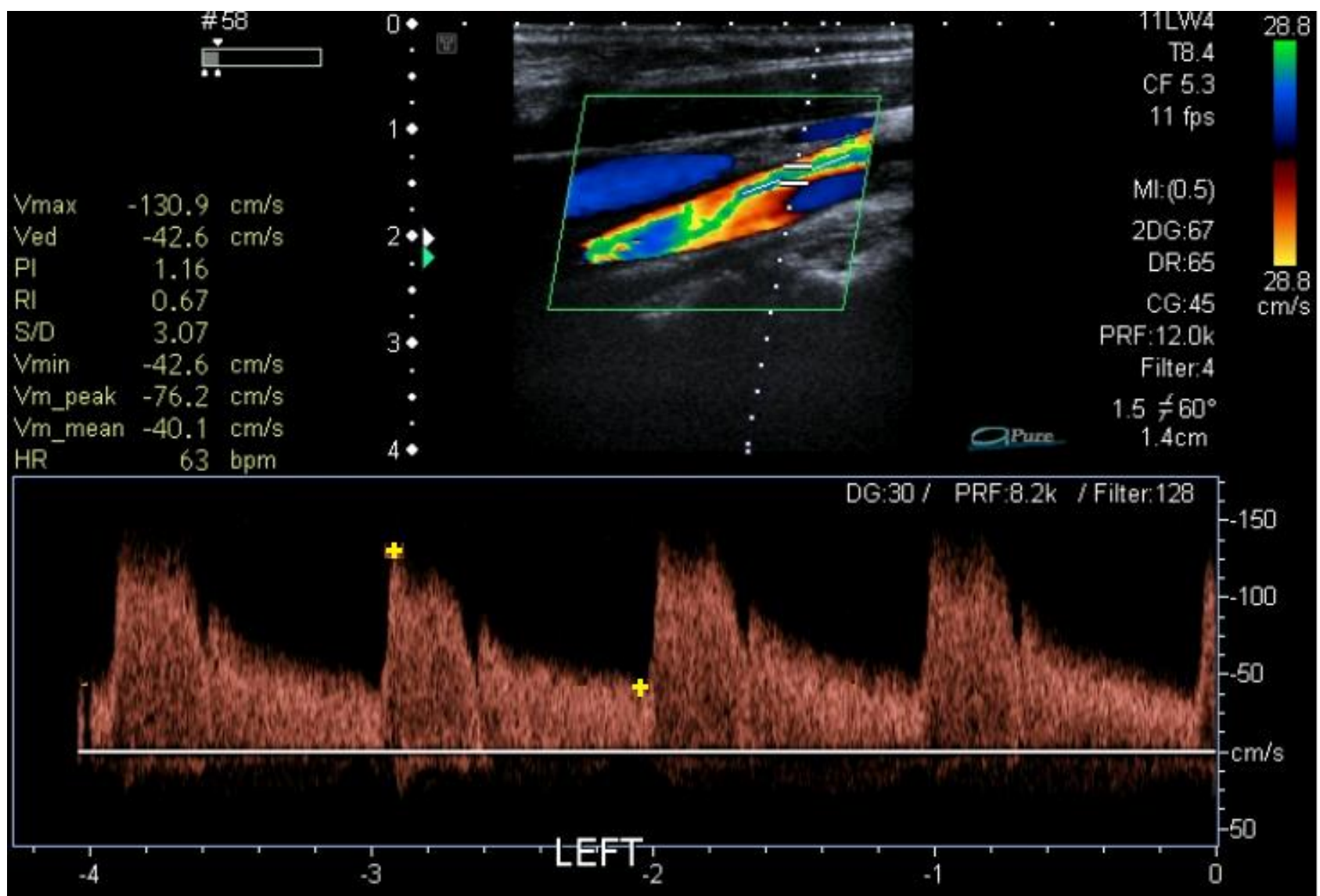

Figure 2. Proximal segment of the left internal carotid artery (left ICA) - color Doppler ultrasound study

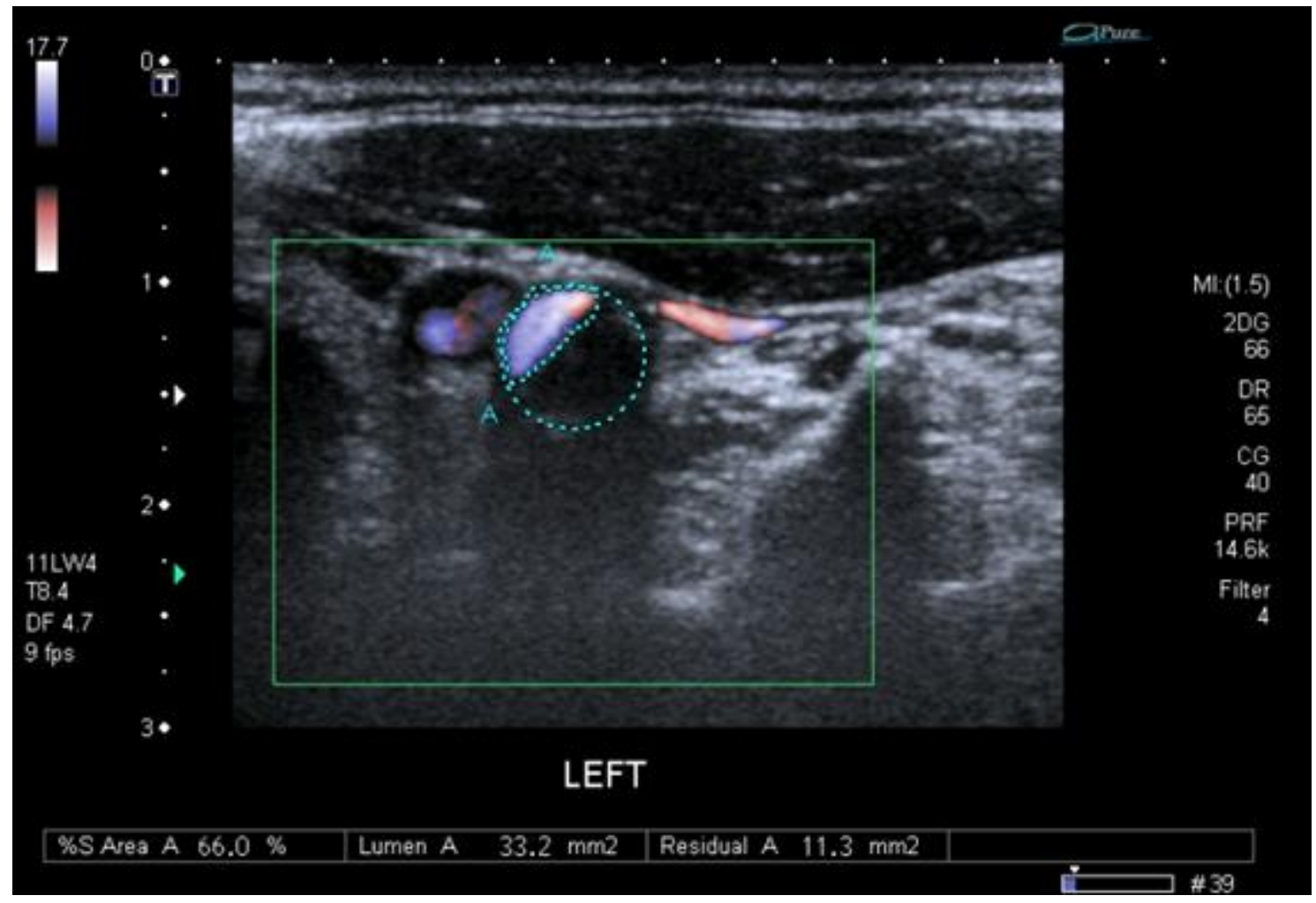

Figure 3. Left common carotid artery (left CCA) - cross-sectional area for the calculation of carotid artery stenosis 


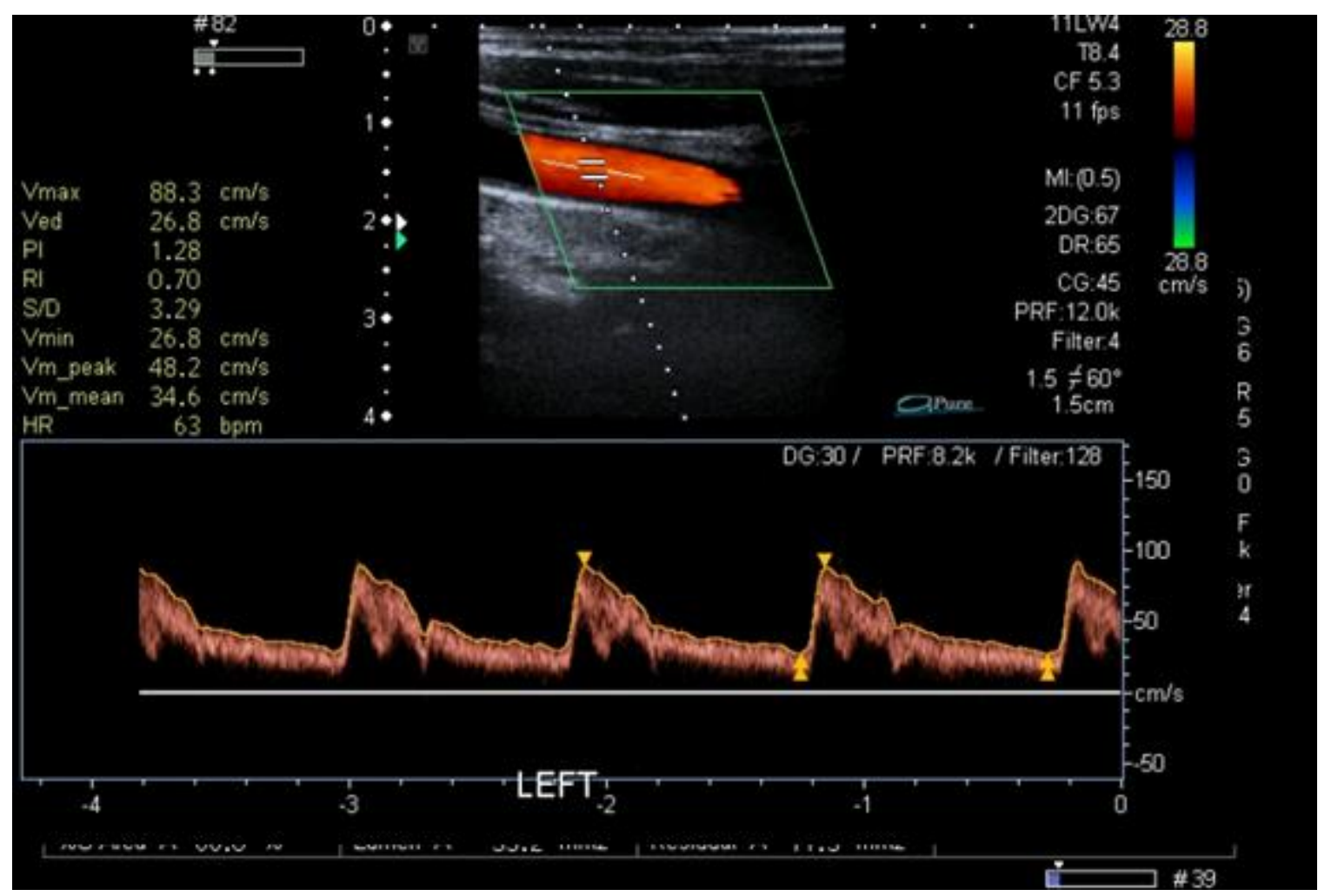

Figure 4. Left common carotid artery (left CCA) - color Doppler ultrasound study

\section{Questions:}

1. Please define what type of the plaque you can see on Figure 1 according to the Geroulakos classification (1).

$$
\begin{aligned}
& \text {-type I } \\
& \text {-type II } \\
& \text {-type III } \\
& \text {-type IV } \\
& \text {-type V }
\end{aligned}
$$

2. What is the degree of stenosis of the left internal carotid artery (ICA) based on Figures 2, 3 and 4?

$$
\begin{aligned}
& -0<50 \% \\
& -50-69 \% \\
& -70 \%
\end{aligned}
$$

3. What would you call the color phenomenon when you see green color in the middle of the vessel, where the sample volume is located (Fig. 2)?
-Reverberation
-Aliasing
-Flow reversal
-Blooming 
4. What would you call the color phenomenon when you see blue color at the posterior wall of the ICA, below the sample volume (Fig.2)?

-Reverberation

-Aliasing

-Flow reversal

-Blooming

5. What statement is more accurate if you compare spectral Doppler appearances of the left ICA (Fig. 2) and the left common carotid artery (Fig. 4).

-a poor acoustic window is demonstrated (Fig. 2)

-turbulent flow is demonstrated (Fig. 2)

-acoustic clarity is demonstrated (Fig. 4) -spectral broadening is demonstrated (Fig. 2)
Ihor Hayda, Mykhaylo Sorokivskyy, Ihor Volodymyr Hayda

Danylo Halytsky Lviv National Medical University, Lviv, Ukraine

Peer-review: internal and external Conflict of interest: None to declare

Authorship: I.H., M.S., and I.V.H. have equally contributed to preparation of quiz

Acknowledgement and funding: None to declare

\section{References}

1.Geroulakos G, Ramaswami G, Nicolaides A, James K, Labropoulos N, Belcaro G, et al. Characterization of symptomatic and asymptomatic carotid plaques using high-resolution real-time ultrasonography. Br J Surg 1993; 80: 1274-7. doi/pdf/10.1161/01.STR.20.2.175 